\title{
El estado de derecho y las violaciones al debido proceso en el juzgamiento de delitos políticos en Venezuela ${ }^{1}$
}

\author{
Héctor Dario Pacheco Peña ${ }^{2}$ \\ Universidad de Carabobo \\ Paola Alexandra Sierra-Zamora ${ }^{3}$ \\ Escuela de Aviación del Ejército
}

\section{Resumen}

El estado de derecho tiene como condición la existencia de un sistema de gobierno democrático que establezca una división relativa del poder que garantice el acceso y respeto a la justicia, no solo porque la estructura del órgano judicial tiene como función dirimir los conflictos y las controversias que se suscitan dentro de la esfera social, sino sobre todo porque ejerce un control fundamental sobre los otros órganos que conforman la dinámica del aparato estatal. Esta investigación aborda (1) la génesis del estado de derecho en el Estado venezolano, (2) la crisis actual por el empleo que se hace de la justicia para perseguir a la oposición política mediante tipos penales preexistentes y sin garantía alguna, y (3) la utilización de fueros militares para el juzgamiento de civiles. Se concluye que la estructura gubernamental venezolana se ha esforzado en retrotraer el estado social a un estado policial, en vez de fortalecer el estado social de derecho y de justicia que ha previsto la Constitución de 1999. La funesta acción política ha permitido que se presenten violaciones al debido proceso en las aprehensiones sin tipo penal aparente, censura previa a medios televisivos, en fin, hechos que demuestran la penalización de

1 Este capítulo forma parte de los resultados del proyecto de investigación "Perspectivas en Derechos Humanos y Derecho Internacional Humanitario para el Ejército Nacional de Colombia”, del grupo de investigación en Aviación Militar de la Escuela de Aviación del Ejército, registrado con el código COL0077618 y categorizado en C por Minciencias. Los puntos de vista pertenecen a los autores y no reflejan necesariamente los de las instituciones participantes.

2 Abogado egresado con Mención Honorífica Summa Cum Laude de la Escuela de Derecho de la Universidad de Carabobo, Valencia, Venezuela. Especialista en Gerencia Tributaria de la Universidad de Carabobo. Profesor de la cátedra de Derecho Penal y Derecho Mercantil en la Escuela de Derecho de la Universidad de Carabobo, Valencia, Venezuela. ORCID: https://orcid.org/0000-0003-3334-6019. Contacto: hdpaa checo@uc.edu.ve

3 Abogada de la Universidad Católica de Colombia. Magíster en Derechos Humanos, Democracia y Justicia Internacional de la Universitat de València, Espańa. Doctorado (en curso) del Programa de Derechos Humanos, Democracia y Justicia Internacional de la Universitat de Valéncia, España. Investigadora de la Escuela de Aviación del Ejército, Bogotá, D. C., Colombia. ORCID: https://orcid.org/0000-0002-3146-7418. Contacto: paolasierrazamora@cedoc.edu.co 
la disidencia política mediante actos que en sí mismos niegan el debido proceso y el régimen jurídico.

Palabras clave: debido proceso; delitos políticos; derechos políticos; estado de derecho; principios procesales constitucionales.

\section{Introducción}

En la evolución contemporánea de la doctrina del Estado moderno se forjó la concepción de un régimen legal que no solo define las relaciones entre la sociedad civil y la sociedad política, sino que además somete al Estado a los frenos y contrapesos que surgen como respuesta a un sinfín de exigencia sociales. Si bien este régimen legal partió del esquema liberal que propugnó la Revolución Francesa como respuesta al absolutismo monárquico, fue adaptado y modificado a medida que las naciones surgían y establecían su ordenamiento jurídico. Sin embargo, la libertad, la legalidad y la igualdad son los principios básicos comunes del sostenimiento de un Estado moderno, los cuales se establecen en una normativa común de aplicación: la constitución escrita.

Particularmente, en los países con una marcada influencia romanística, la constitución hace un amplio desarrollo de los derechos y las garantías que tiene el ciudadano, para lo cual establece un cuerpo dogmático de libertades que profundizan su desarrollo individual y colectivo. En este sentido, solo se puede hablar de estado de derecho en la concepción de un sistema de gobierno democrático porque este, a pesar de las imperfecciones propias de todos los sistemas, establece una división relativa del poder, que ejercen los representantes elegidos por el pueblo, entendido como colectivo y titular de la soberanía.

No obstante, en la concepción democrática se debe distinguir la visión republicana, una forma principista plena en la que ese conjunto de representantes y/o funcionarios está al servicio de un ente mayor que es el Estado y que obedece, más que a los fines o intereses propios, a la voluntad del pueblo. En palabras de Abraham Lincoln, cuando definió la democracia en el discurso de Gettysburg el 19 de noviembre de 1863: "El gobierno del pueblo, por el pueblo y para el pueblo".

Es indubitable que el estado de derecho solo tiene lugar en un régimen democrático, en el cual se configura en un nivel superior el estado social de derecho y de justicia, que es el fundamento de las garantías a las libertades públicas y a los derechos fundamentales, por parte del Estado y de los particulares. Por lo tanto, la organización jurídica del Estado no existe si no hay una constitución escrita que responda a los intereses de la población, como tampoco se puede considerar 
democrático sin que la población elija a sus representantes en elecciones directas, universales y secretas, y, sobre todo, sin que los órganos que integran el poder sean independientes y establezcan controles mutuos. De allí que sea necesario hacer especial énfasis en la autonomía plena que deben tener los jueces para solucionar los conflictos y las controversias dentro de la sociedad, por cuanto constituye la garantía mínima que tiene el ciudadano para desarrollarse.

En este sentido, la democracia y su ejercicio presuponen la justicia, no solo porque la estructura del órgano judicial tiene la función de dirimir los conflictos y las controversias que se suscitan dentro de la esfera social, sino sobre todo porque ejerce un control fundamental sobre los otros órganos que conforman la dinámica del aparato estatal.

Venezuela no escapa de esta situación, pues desde que la Constitución de 1999 entró en vigencia se profundizó un proceso de división pentapartita, es decir, se incluyeron dos nuevos órganos a los tres tradicionales - ejecutivo, legislativo y judicial—: ciudadanos y electoral. En este sentido, aunque la Constitución venezolana es una muestra de la idoneidad de un sistema social de vanguardia, el proceso social ha conllevado grandes desviaciones de los acuerdos que se preceptuaron en el plano constitucional y que han incidido directamente en el plano del derecho penal. Esta situación se ha traducido en un fenómeno de ingobernabilidad, frente al cual la estructura gubernamental se ha esforzado en retrotraer el estado social a un estado policial, en vez de fortalecer el estado social de derecho y de justicia que ha previsto la carta magna.

Sostenemos esta tesis basándonos fundamentalmente en la denuncia que hizo el Estado venezolano al Pacto de San José, que oficializó su retiró del Sistema Interamericano de Derecho Humanos. De igual forma, nuestra tesis también se sustenta en que ha eludido las decisiones que el Sistema Interamericano ha tomado en diversos casos, con lo cual ha trascendido a un régimen donde las garantías están limitadas por las particularidades del juzgador de turno direccionado por el gobierno. Este tratamiento ha obviado los criterios relacionados por el sistema interamericano, tanto de la Comisión como de la Corte, de manera que si bien Venezuela salió del sistema, es ineludible que la carta magna vigente propugna el reconocimiento de los tratados en materia de Derechos Humanos. Asimismo, la funesta acción política ha permitido que se presenten violaciones al debido proceso en las aprehensiones sin tipo penal aparente, censura previa a medios televisivos, en fin, hechos que demuestran la penalización de la disidencia política mediante actos que en sí mismos niegan el debido proceso y el régimen jurídico.

Con base en la tesis propuesta, la investigación aborda (1) la génesis del estado de derecho en el Estado venezolano, (2) la crisis actual por el empleo que se hace 
de la justicia para perseguir a la oposición política mediante tipos penales preexistentes y sin garantía alguna, y (3) la utilización de fueros militares para el juzgamiento de civiles.

La crisis política ha derivado en una crisis institucional en la que los operadores políticos han permeado los procesos judiciales. Como consecuencia, han menoscabado los derechos propios que tienen los ciudadanos y han aplicado e interpretado conductas dentro de tipos penales que no concuerdan con su naturaleza jurídica. En este sentido, el objetivo del artículo es mostrar la realidad jurídica de un Estado policía y forjar una alternativa para que el resto de las comunidades de países que conforman América del Sur se identifiquen y construyan mecanismos constitucionales y legales que establezcan los controles necesarios para evitar sistemas policiales que criminalicen el disentimiento, de tal manera que si existe la comisión de delitos, se garantice el respeto del proceso en la legalidad y legitimidad de los operadores de justicia.

\section{Antecedentes históricos del estado de derecho}

Los principales exponentes de la teoría del estado de derecho son los alemanes Robert von Mohl, Rudolf Stahl y Von Sarwey Gneist. El primero de ellos acuñó el término estado de derecho, o Rechtsstaat - título de su célebre obra que apareció en el año 1832 - y desde entonces se ha aplicado con frecuencia en la terminología jurídica. Al respecto, Villar (2007) afirma que en la génesis terminológica del estado de derecho se puede distinguir el estado absoluto y/o de policía del estado de derecho: mientras en el primero se presenta la discrecionalidad del funcionario, independientemente de lo justo o injusto, en el estado de derecho hay reglas preexistentes que subordinan la actuación de los funcionarios.

\section{Concepto de estado de derecho}

Carré de Malberg (1948; citado por Rivas, 2008) define el estado de derecho de la siguiente manera:

Debe entenderse un Estado que, en sus relaciones con sus súbditos y para garantías del estatuto individual de estos, se somete él mismo a un régimen de Derecho, por cuanto encadena su acción respecto a ellos por un conjunto de reglas, de las cuales unas determinan los derechos otorgados a los ciudadanos y otras establecen previamente las vías y medios que podrán emplearse con vistas a realizar los fines estatales: dos clases de reglas que tienen, por efecto común, limitar la potestad del Estado subordinándola al orden jurídico que consagran. (p. 181) 
En el constitucionalismo moderno, el estado de derecho parte de la autolimitación del Estado, la cual se entiende como un acto propio que enérgicamente hace el Estado frente a los gobernados, es decir, subordina su actuación al derecho que él mismo crea. En este sentido, Linares Quintana (1953; citado por Rivas, 2008) sostiene que el estado de derecho implica la autoobligación del Estado con respecto a su derecho, concepción elaborada principalmente por los jurisconsultos alemanes Mohl, Stahl, Gneist, Bahr y Jellinek. En palabras de este último:

No solo trata este de contener la omnipotencia del Estado mediante la fijación de normas para la exteriorización de su voluntad, sino que trata de refrenarlo muy especialmente, mediante el reconocimiento de derechos individuales garantizados. Esta garantía consiste en otorgar a los derechos protegidos el carácter de inmutables. (Jellinek; citado por Rivas, 2008, p. 182)

Es decir, la autolimitación que ejerce el Estado sobre un régimen jurídico subyace en la constitución escrita, por cuanto este cuerpo normativo, dentro de la configuración de la ley positiva, tiene el plano de legalidad condicionante que hace que todo el ordenamiento jurídico este subordinado a la legalidad. En tal sentido, cualquier cuerpo normativo, sea el caso general o especial de Venezuela, está condicionado a concordar con la referencia constitucional, de lo contrario menoscabaría y se sometería al vicio de inconstitucionalidad, basado en la teoría de la supremacía constitucional.

Solo se puede configurar un estado de derecho si existe un régimen democrático. En ese sentido, Orlando Monagas Rodríguez (2015) sostiene que en la Constitución venezolana la democracia pasa de ser una aspiración a un elemento normativo, es decir, se normativiza el término democracia como presupuesto imprescindible de la Constitución auténtica, cuya legitimidad deriva de la soberanía popular. En este punto es oportuno aclarar que en el estado constitucional el pueblo no ejerce un poder absoluto, como el que se predicaba en el estado absoluto, que está en abierta contradicción con el estado democrático.

El tratadista comenta que a raíz de la constitucionalización del término democracia se fundieron en una misma moneda la democracia y la soberanía del pueblo. Siguiendo a Baumlin (1990), Georges Burdeau (1961; citado por Monagas, 2015, p. 79) insiste en que hay estado constitucional siempre y cuando la realidad política esté apegada a la realidad jurídica. Por lo tanto, al inspirarse en un sistema democrático donde los ciudadanos eligen a sus representantes y estos pueden participar en igualdad de condiciones, es indiscutible que el Estado constitucional excluye la monocracia y por consiguiente el ejercicio salvaje del poder. Consecuentemente, el caudillismo solo puede existir fuera del estado constitucional o de derecho, porque 
en este sistema no es posible atribuirse la concentración de poderes o la configuración de poderes manipulados.

Es decir, la existencia de un régimen de derecho dentro del estado de derecho se somete a elementos específicos que actúan de forma conjunta, de tal manera que la ausencia de uno de ellos vulnera la existencia del Estado y condiciona el régimen en sí mismo. Estos factores son: (1) la libertad, (2) la igualdad ante la ley, (3) la división de poderes y (4) la supremacía y control de la constitucionalidad de las leyes y los actos. Complementariamente, Pedro Luis Bracho Grand (2000, p. 42), distingue entre principios constitutivos y derivados. Dentro de los constitutivos se encuentran:

a. Los derechos fundamentales, entre los cuales se evidencia la propiedad, la seguridad y la libertad.

b. Separación de poderes, es decir, que cada poder debe ser independiente, igual y autónomo.

c. Autoridad de la ley, que se refiere a que todo acto del Estado debe estar conforme a la ley.

En cuanto a los principios derivados, el autor precisa los siguientes:

a. Reserva legal: solo se pueden regular por ley general aquellas que tienen que ver con las garantías ciudadanas.

b. Irretroactividad de la ley: garantía de la aplicación de la ley en situaciones anteriores a esta.

c. Independencia de los jueces: garantía de imparcialidad y no interferencia de la función jurisdiccional.

d. Jerarquía de las normas: las normas deben ser aplicadas de acuerdo con el orden jerárquico, en relación con el cual se validan.

e. Legalidad de la administración: la administración pública responde por sus actos, estos se someten a normas preexistentes y están sujetos a control judicial.

f. Justicia constitucional: los jueces son guardianes del orden constitucional.

Estos elementos demuestran que si se analiza un régimen jurídico y se observa objetivamente la ausencia de alguno de estos principios, se puede concluir que no existe estado de derecho, sino que se trata de un estado arbitrario. Es importante destacar que, como se señaló, el estado de derecho se diferencia fundamentalmente por el ejercicio pleno del individuo frente al Estado, de manera que su máximo 
desarrollo es el reconocimiento de la existencia de este ante el imperio de la ley. No obstante, cabe destacar que el ejercicio de la acción y el proceso judicial en su sentido amplio son los mecanismos que tiene el régimen para asegurar el respeto de los derechos y las garantías consagrados en la Constitución y en las distintas leyes que conforman el ordenamiento jurídico. Sin embargo, conviene aclarar que la existencia del estado de derecho no significa que el ciudadano pueda ser afectado por algún ente de la administración, por ejemplo en el derecho a tránsito, sino que frente a la lesividad al derecho que tiene como ciudadano, se le brinda la facultad de acudir a una instancia jurisdiccional para que esta ejerza pleno control sobre este, revierta esa lesión y se le restituya el derecho.

\section{El constitucionalismo y las garantías en Venezuela}

Venezuela registra desde 1811 un sistema republicano, derivado del proceso independentista de España. Este proceso histórico devino hasta la fecha en un conjunto de constituciones escritas que tenían una marcada influencia de los principios de la Revolución Francesa y Norteamericana. Sin embargo, a pesar de la premisa totalitaria, es necesario entender que a partir de las constituciones promulgadas en 1961 y en 1999 el proceso social y político ha devenido en un conjunto de garantías civiles —entendidas como derechos fundamentales - e individuales - políticas, sociales, educativas, laborales, entre otras-.

Estas garantías constituyen un derecho para la sociedad civil, que deberá exigir a los funcionarios públicos el ejercicio de políticas públicas que permitan el libre desenvolvimiento de los ciudadanos. Ahora bien, el derecho del particular se materializa en diversas herramientas constitucionales — como el ejercicio dentro del proceso judicial—, entendido como instrumento fundamental del estado social de derecho y de justicia, no solo en la acción sino en la defensa misma, para lo cual debe garantizar que las personas satisfagan sus necesidades o facilitar que autogestionen las soluciones que les permitan hacerlo.

\section{La Constitución de 1999 y el estado democrático social de derecho y de justicia}

A raíz del proceso constituyente que derivó en la actual Constitución de 1999, en Venezuela se estableció un estado social de derecho y de justicia, como determina el artículo 2. ${ }^{\circ}$ de la Constitución de la República Bolivariana de Venezuela (1999): 
Venezuela se constituye en un Estado democrático y social de Derecho y de Justicia, que propugna como valores superiores de su ordenamiento jurídico y de su actuación, la vida, la libertad, la justicia, la igualdad, la solidaridad, la democracia, la responsabilidad social y, en general, la preeminencia de los Derechos Humanos, la ética y el pluralismo político.

Esta concepción del estado social está influida por dos constituciones de reciente data, como son la de Espańa en 1978 y la de Colombia en 1991, en las cuales se hace esta definición en el artículo 1.․ Con respecto a esta comprensión del estado social, Allan Brewer Carias (2000, p. 47; citado por Rivas, 2004) sostiene que "la idea de estado social es la de un Estado con obligaciones sociales, de procura de la justicia social, lo que lleva a intervenir en la actividad económica y social como Estado prestacional" (p. 165).

Sin duda, los alcances de la "justicia social” son la razón de ser del estado social de derecho y de justicia, ya que exige que haya equilibrio en las relaciones entre el gobernante y los gobernados, lo cual demuestra la paridad que debe existir entre los derechos o garantías y las obligaciones y/o atribuciones. Asimismo, en un régimen democrático no puede haber justicia social sin que exista su complemento: la amplia participación de las mayorías con respeto a las minorías, es decir, el sufragio y los mecanismos de participación política y ciudadana. Así lo plantea el artículo 5. ${ }^{\circ}$ de la Constitución de la República Bolivariana de Venezuela (1999):

La soberanía reside intransferiblemente en el pueblo, quien la ejerce directamente en la forma prevista en esta Constitución y en la ley, e indirectamente, mediante el sufragio, por los órganos que ejercen el Poder Público.

Los órganos del Estado emanan de la soberanía popular y a ella están sometidos.

Como se observa, es bastante novedoso que en la vida republicana se afirme que la sociedad gobernante es controlada por la soberanía popular, es decir, la visión de que la actuación de sus distintos representantes es vigilada plenamente por sus electores, pues a ellos se deben. Sin embargo, el artículo $7 .^{\circ}$ recuerda que "la Constitución es la norma suprema y el fundamento del ordenamiento jurídico. Todas las personas y los órganos que ejercen el Poder Público están sujetos a esta Constitución”.

En este punto es fundamental destacar que el estado de derecho y de justicia son concepciones sinónimas, como también lo son respecto a la noción de estado constitucional, como argumenta Bidart Campos (1968; citado por Quintero, 2004):

Nos parece que la sinonimia no es feliz, aunque todo depende del significado que se atribuya al estado de derecho. Creemos que la imagen del estado de derecho en su 
interpretación liberalista — que es la originaria y la dominante- postula esencialmente la limitación del Estado por su propia voluntad; el Estado labora su propia regulación, el derecho positivo y se da una autolimitación. (p. 166)

$\mathrm{Al}$ respecto de esta referencia, se debe señalar que no es suficiente el cuerpo normativo o derecho que establece el Estado en sí mismo, sino que además se hace necesario que las actuaciones de los órganos que ejercen el poder público y de los particulares demuestren el acatamiento sostenido de las limitaciones que este impone. De ser así, se podría considerar que hay un estado de derecho y/o constitucional, pues se observa objetivamente que los postulados constitucionales tienen plena vigencia. De lo contrario, si el Estado restringe o suprime la libertad, constituiría entonces un estado totalitario, que es la antítesis del estado de derecho.

Pero más allá de la autolimitación que se impone el Estado — tanto en la creación de normas como en su ejecución y aplicación-, también es necesario que ese derecho responda a un criterio de profunda legitimidad y, por lo tanto, que haya un criterio claro de legitimación. En este sentido, Lipson (1964, p. 93; citado por Chalbaud, 1999, p. 62) asevera que la autoridad es una cáscara vacía si carece de poder, de manera que se puede desafiar al poder con impunidad si no es capaz de esgrimir la fuerza. Pero esta relación autoridad-poder-fuerza debe ser examinada, para que el consentimiento de los gobernados se pueda expresar en forma libre.

Además, es importante señalar que la legitimidad del poder se debe aplicar a la legitimidad del derecho, pues, como argumenta Luis Recasens Siches (1960; citado por Chalbaud, 1999, p. 62), la organización y la legitimación del poder son dos de las necesidades que trata de satisfacer el derecho. De acuerdo con este autor, el Estado está representado por un grupo de personas investidas con características especiales, los funcionarios, quienes elaboran representaciones y voliciones que obligan a todos los miembros de la sociedad. En ese orden de ideas, a diferencia de los anteriores, los miembros de la colectividad obedecen habitualmente los mandatos de esos funcionarios debido a la intervención del derecho, que se presenta ante los individuos como la imagen de lo legítimo. En consecuencia, el poder del Estado (plasmado en las representaciones y voliciones elaboradas por los funcionarios) no puede surgir sin la ayuda del derecho, pues es este precisamente el que organiza el poder, es decir, asigna a cada una de sus ramas las atribuciones y competencias necesarias y convenientes para que puedan funcionar adecuadamente y lograr los fines que le son propios al Estado. En síntesis, el derecho permite la normal actuación dentro del cuerpo político.

Como se mencionó, el texto constitucional en estudio señala que es un estado de justicia, término que entrañan los órdenes de conductas rectas y justas, en oposi- 
ción a los estados totalitarios, que denota los regímenes de entuerto a la justicia, como sostiene Goldschmidt (citado por Rivas, 2004, p. 167). Sin embargo, esta noción de justicia implica en la práctica que se legitimen con idoneidad el derecho $y$, por ende, el estado de derecho, el cual se basa fundamentalmente en la justicia. En tal virtud, si la organización del poder por parte del derecho se ajusta a formas intrínsecamente justas, automáticamente el poder puede considerarse legítimo.

Al respecto se debe señalar que el valor de la justicia es precisamente el principio que legitima el orden político y social, pues por su efecto tal orden se hace jurídico, como señala Francisco Ayala (1959; citado por Chalbaud, 1999, p. 241). Este autor resalta además que los principios de legitimación del poder funcionan al mismo tiempo como principios inmediatos de la organización realizada por el derecho.

No obstante, para que esta utopía se configure en una realidad es necesario que haya un aporte considerable de aquellos elementos que anteriormente denominamos como principios. Sin duda, como resultado se obtiene el proceso judicial, instrumento legal y a la vez constitucional de dirimir los conflictos y controversias en la vida social, específicamente dentro del ámbito espacial de la norma. El proceso como aspiración conduce a un debido proceso que no solo dinamiza el deber ser mediante determinados preceptos, sino que además satisface la necesidad de justicia y legitima las relaciones sociales, pues si bien hace un juicio valorativo sobre las normas vigentes, también enjuicia a los funcionarios y a la legitimidad del ejercicio con que actúan en el ámbito de lo justo y lo injusto.

\section{Aspectos generales del debido proceso}

El fundamento ideal del proceso es el debido proceso, que la Constitución de la República Bolivariana de Venezuela garantiza. Al respecto, Monagas (2015) sostiene que el debido proceso comprende el directo reconocimiento de los derechos fundamentales que corresponden al ciudadano, de modo que es la expresión jurídica más clara del proceso penal garantizado por la Constitución. No es una tarea fácil describir este complejo término porque en sí mismo hace referencia a un principio general que informa toda la estructura del ordenamiento jurídico procesal, así como a los derechos fundamentales y a las respectivas garantías que debe otorgar el proceso penal consagrado en la Constitución. Como sostiene Claus Roxin (2000; citado por Monagas, 2015):

En el procedimiento penal entran en conflicto los intereses colectivos e individuales entre sí con más intensidad que en ningún otro ámbito, la ponderación de esos 
intereses establecida por la ley resulta sintomática para establecer la relación entre Estado e individuo genéricamente vigente en una comunidad: ¡El derecho procesal penal es el sismógrafo de la Constitución del Estado! Reside en ello su actualidad política, la cual significa, al mismo tiempo, que cada cambio esencial en la estructura política (sobre todo una modificación de la estructura del Estado) también conduce a transformaciones del procedimiento penal. (p. 86)

En conclusión, el debido proceso, más que una mera orientación, es sin duda el mecanismo de dirección para interpretar las normas que consagran los derechos fundamentales y las garantías, además de que impone efectivamente el respeto y la aplicación en todo el tracto del proceso penal. En lo que respecta a la Constitución de la República Bolivariana de Venezuela (1999), los derechos fundamentales consignados evidencian la garantía de que existe no solo un proceso penal, sino que es justo:

Artículo 49. El debido proceso se aplicará a todas las actuaciones judiciales y administrativas; en consecuencia:

1. La defensa y la asistencia jurídica son derechos inviolables en todo estado y grado de la investigación y del proceso. Toda persona tiene derecho a ser notificada de los cargos por los cuales se le investiga; de acceder a las pruebas y de disponer del tiempo y de los medios adecuados para ejercer su defensa. Serán nulas las pruebas obtenidas mediante violación del debido proceso. Toda persona declarada culpable tiene derecho a recurrir del fallo, con las excepciones establecidas en esta Constitución y en la ley.

2. Toda persona se presume inocente mientras no se pruebe lo contrario.

3. Toda persona tiene derecho a ser oída en cualquier clase de proceso, con las debidas garantías y dentro del plazo razonable determinado legalmente por un tribunal competente, independiente e imparcial establecido con anterioridad. Quien no hable castellano, o no pueda comunicarse de manera verbal, tiene derecho a un intérprete.

4. Toda persona tiene derecho a ser juzgada por sus jueces naturales en las jurisdicciones ordinarias o especiales, con las garantías establecidas en esta Constitución y en la ley. Ninguna persona podrá ser sometida a juicio sin conocer la identidad de quien la juzga, ni podrá ser procesada por tribunales de excepción o por comisiones creadas para tal efecto.

5. Ninguna persona podrá ser obligada a confesarse culpable o declarar contra sí misma, su cónyuge, concubino o concubina, o pariente dentro del cuarto grado de consanguinidad y segundo de afinidad.

6. La confesión solamente será válida si fuere hecha sin coacción de ninguna naturaleza.

7. Ninguna persona podrá ser sancionada por actos $\mathrm{u}$ omisiones que no fueren previstos como delitos, faltas o infracciones en leyes preexistentes. 
8. Ninguna persona podrá ser sometida a juicio por los mismos hechos en virtud de los cuales hubiese sido juzgada anteriormente.

9. Toda persona podrá solicitar del Estado el restablecimiento o reparación de la situación jurídica lesionada por error judicial, retardo u omisión injustificados. Queda a salvo el derecho del o de la particular de exigir la responsabilidad personal del magistrado o de la magistrada, del juez o de la jueza; y el derecho del Estado de actuar contra estos o estas.

Además de estas consideraciones, es necesario agregar que la carta magna de 1999 ha establecido otras garantías que se entrelazan con el debido proceso y los derechos fundamentales:

Artículo 19. El Estado garantizará a toda persona, conforme al principio de progresividad y sin discriminación alguna, el goce y ejercicio irrenunciable, indivisible e interdependiente de los Derechos Humanos. Su respeto y garantía son obligatorios para los órganos del Poder Público, de conformidad con esta Constitución, con los tratados sobre Derechos Humanos suscritos y ratificados por la República y con las leyes que los desarrollen.

Artículo 22. La enunciación de los derechos y garantías contenidos en esta Constitución y en los instrumentos internacionales sobre Derechos Humanos no debe entenderse como negación de otros que, siendo inherentes a la persona, no figuren expresamente en ellos. La falta de ley reglamentaria de estos derechos no menoscaba el ejercicio de los mismos.

Artículo 23. Los tratados, pactos y convenciones relativos a Derechos Humanos, suscritos y ratificados por Venezuela, tienen jerarquía constitucional y prevalecen en el orden interno, en la medida en que contengan normas sobre su goce y ejercicio más favorables a las establecidas en esta Constitución y en las leyes de la República, y son de aplicación inmediata y directa por los tribunales y demás órganos del Poder Público.

Artículo 26. Toda persona tiene derecho de acceso a los órganos de administración de justicia para hacer valer sus derechos e intereses, incluso los colectivos o difusos; a la tutela efectiva de los mismos y a obtener con prontitud la decisión correspondiente.

El Estado garantizará una justicia gratuita, accesible, imparcial, idónea, transparente, autónoma, independiente, responsable, equitativa y expedita, sin dilaciones indebidas, sin formalismos o reposiciones inútiles.

Artículo 27. Toda persona tiene derecho a ser amparada por los tribunales en el goce y ejercicio de los derechos y garantías constitucionales, aun de aquellos inherentes a la persona que no figuren expresamente en esta Constitución o en los instrumentos internacionales sobre Derechos Humanos.

El procedimiento de la acción de amparo constitucional será oral, público, breve, gratuito y no sujeto a formalidad; y la autoridad judicial competente tendrá potestad para restablecer inmediatamente la situación jurídica infringida o la situación que 
más se asemeje a ella. Todo tiempo será hábil y el tribunal lo tramitará con preferencia a cualquier otro asunto.

La acción de amparo a la libertad o seguridad podrá ser interpuesta por cualquier persona; y el detenido o detenida será puesto o puesta bajo la custodia del tribunal de manera inmediata, sin dilación alguna.

El ejercicio de este derecho no puede ser afectado, en modo alguno, por la declaración del estado de excepción o de la restricción de garantías constitucionales.

Artículo 44. La libertad personal es inviolable; en consecuencia:

1. Ninguna persona puede ser arrestada o detenida sino en virtud de una orden judicial, a menos que sea sorprendida in fraganti. En este caso, será llevada ante una autoridad judicial en un tiempo no mayor de cuarenta y ocho horas a partir del momento de la detención. Será juzgada en libertad, excepto por las razones determinadas por la ley y apreciadas por el juez o jueza en cada caso.

La constitución de caución exigida por la ley para conceder la libertad de la persona detenida no causará impuesto alguno.

1. Toda persona detenida tiene derecho a comunicarse de inmediato con sus familiares, abogado o abogada, o persona de su confianza; y estos o estas, a su vez, tienen el derecho a ser informados o informadas sobre el lugar donde se encuentra la persona detenida; a ser notificados o notificadas inmediatamente de los motivos de la detención y a que dejen constancia escrita en el expediente sobre el estado físico y psíquico de la persona detenida, ya sea por sí mismos o por sí mismas, o con el auxilio de especialistas.

2. La autoridad competente llevará un registro público de toda detención realizada, que comprenda la identidad de la persona detenida, lugar, hora, condiciones y funcionarios o funcionarias que la practicaron.

3. Respecto a la detención de extranjeros o extranjeras se observará, además, la notificación consular prevista en los tratados internacionales sobre la materia.

4. La pena no puede trascender de la persona condenada. No habrá condenas a penas perpetuas o infamantes. Las penas privativas de la libertad no excederán de treinta años.

5. Toda autoridad que ejecute medidas privativas de la libertad estará obligada a identificarse.

6. Ninguna persona continuará en detención después de dictada orden de excarcelación por la autoridad competente, o una vez cumplida la pena impuesta.

En ese orden de ideas, cabe mencionar algunas consideraciones que la Sala Constitucional del Tribunal Supremo de Justicia de la República Bolivariana de Venezuela ha referido sobre la tutela judicial efectiva, como garante del debido proceso:

En efecto, el derecho a la tutela judicial efectiva no se agota en un simple contenido o núcleo esencial, sino que, por el contrario, abarca un complejo número de derechos dentro del proceso, a saber: i) el derecho de acción de los particulares de 
acudir a los órganos jurisdiccionales para obtener la satisfacción de su pretensión, ii) el derecho a la defensa y al debido proceso en el marco del procedimiento judicial, iii) el derecho a obtener una sentencia fundada en derecho, iv) el derecho al ejercicio de los medios impugnativos que establezca el ordenamiento jurídico, v) el derecho a la ejecución de las resoluciones judiciales y, vi) el derecho a una tutela cautelar. (Sentencia 423 del 2009)

Asimismo, se debe garantizar el derecho a la defensa, el cual tiene una vinculación inmediata y directa con el derecho a la tutela judicial efectiva, y dentro del cual suele incluirse el derecho a la presentación de las pruebas que se estimen pertinentes y que estas sean apreciadas en el marco del procedimiento correspondiente. De lo contrario, se generaría indefensión y desigualdad procesal entre las partes (Sentencia 423 del 2009).

Se establece, entonces, que el debido proceso constituye un principio constitucional aplicable a todas las actuaciones judiciales y administrativas. Así mismo, comprende una serie de presupuestos que avalan el derecho de toda persona a ser oída durante todo el proceso, además que le otorga el tiempo y los medios adecuados para ejercer la defensa de sus intereses.

En cuanto a la tutela judicial efectiva, se colige que es una garantía fundamental que tienen todos los ciudadanos vinculados en un proceso de que, entre otros aspectos, los jueces y tribunales de la República proferirán una decisión que sea motivada, congruente, ajustada a derecho y que se pronuncie sobre el fondo de las pretensiones de las partes, de manera favorable o no a alguno de ellos. Así, por estar ambos íntimamente vinculados, se debe garantizar el derecho que tienen las partes de presentar las pruebas que estimen pertinentes para que sean valoradas en el procedimiento correspondiente, de manera que no se cause indefensión ni desigualdad procesal entre las partes y que se pueda dictar una decisión correcta.

Ahora bien, respecto a tal violación de las garantías constitucionales, resulta pertinente citar la obra de Humberto Bello Tabares (2004), Tutela judicial efectiva y otras garantías constitucionales procesales, donde señala:

Los principios - como se ha expresado en otra oportunidad - son los criterios, directrices, reglas y orientaciones que rigen tanto las diversas situaciones que pueden surgir en el proceso, como la actuación de las partes, sus representantes judiciales y operadores de justicia, los cuales — como se viene expresando- no solo son de carácter procesal puro, generales y específicos de cada procedimiento, sino de carácter constitucional — garantías o derechos constitucionales procesales- que permiten el buen funcionamiento y desenvolvimiento del proceso, garantizando los derechos fundamentales de los ciudadanos. 
$[\ldots]$.

Luego, estos principios que se enmarcan en los derechos o garantías constitucionales procesales, de manera general pero no limitativa ni restrictiva se ubican en los artículos 26 y 49 de la Constitución de la República Bolivariana de Venezuela, que recogen los derechos mínimos que deben ser garantizados a los justiciables en los estrados judiciales, que deben ser conocidos por el operador de justicia, acatados, aplicados y no vulnerados, so pena de activar el derecho del ciudadano, de poner en funcionamiento el aparato jurisdiccional [...] bien mediante el ejercicio de los recursos ordinarios o mediante el ejercicio de recursos o acciones constitucionales especiales, extraordinarias, excepcionales, pues el juzgador en el ejercicio de la vía ordinaria y no constitucional, también es un garante del texto fundamental, es sujeto obligado a garantizar y proteger, más aún, amparar al ciudadano en el pleno goce de sus derechos constitucionales procesales.

De la cita doctrinal antes transcrita, se desprenden dos cosas, en primer lugar que es estrictamente necesario e incluso un deber de los operadores de justicia garantizar los derechos y garantías constitucionales que amparan al justiciable, y en segundo lugar que los Tribunales Colegiados sin necesidad de que actúen en sede constitucional, también deben garantizar, proteger y amparar a todos los ciudadanos los derechos y garantías constitucionales que los envisten de facultades para hacer valer sus derechos. (Bello, 2004, p. 123)

Ahora bien, en relación con el derecho a la defensa como manifestación del debido proceso, la Sala Constitucional del Tribunal Supremo de Justicia (Sentencia 5 del 2001) ha sido tajante al afirmar:

Es menester indicar que el derecho a la defensa y al debido proceso constituyen garantías inherentes a la persona humana y en consecuencia, aplicables a cualquier clase de procedimientos [...].

En cuanto al derecho a la defensa, la jurisprudencia ha establecido que el mismo debe entenderse como la oportunidad para el encausado o presunto agraviado de que se oigan y analicen oportunamente sus alegatos y pruebas. En consecuencia, existe violación del derecho a la defensa cuando el interesado no conoce el procedimiento que pueda afectarlo, se le impide su participación o el ejercicio de sus derechos, o se le prohíbe realizar actividades probatorias. (Sentencia 5 del 2001)

Siguiendo en este orden y dirección, la misma Sala Constitucional del Tribunal Supremo de Justicia, en Sentencia 1745, del 20 de septiembre de 2001, estableció:

El derecho al debido proceso, consagrado en el artículo 49 de la Constitución a favor de todo habitante de la República, comprende el derecho a defenderse ante los órganos competentes, que serán los tribunales o los órganos administrativos, según el caso. Este derecho implica notificación adecuada de los hechos imputados, disponibilidad de medios que permitan ejercer la defensa adecuadamente, acceso 
a los órganos de administración de justicia, acceso a pruebas, previsión legal de los lapsos adecuados para ejercer la defensa, restablecimiento de los medios de prueba que permitan recurrir contra los fallos condenatorios (de conformidad con las previsiones legales), derecho a ser presumido inocente mientras no se demuestre lo contrario, derecho a ser oído, derecho a ser juzgado por el juez natural, derecho a no ser condenado por un hecho no previsto en la ley como delito o falta, derecho a no ser juzgado dos veces por los mismos hechos, derecho a no ser obligado a declararse culpable ni a declarar contra sí mismo. (Sentencia 1745 del 2001)

De dichas sentencias, emanadas de la máxima instancia judicial de la República, se evidencia que el debido proceso constituye la herramienta esencial de un proceso penal, es decir, la herramienta que el Estado le brinda al justiciable para que le respeten los derechos y las garantías que establece la carta magna. Tal como ha referido la doctrina venezolana:

El debido proceso no es un fin en sí mismo, no es un conjunto de actos que tienen función y finalidad propia, por el contrario, producto de su constitucionalizarían (sic), constituye una herramienta, un instrumento utilizable para alcanzar uno de los valores fundamentales y superiores del ordenamiento jurídico constitucional, a partir del cual se construye el texto constitucional contentivo de los derechos y garantías fundamentales. (Bello, 2004, p. 350)

En consecuencia, el derecho a la defensa es un derecho de rango constitucional, debidamente consagrado en el artículo 49.1 de la Constitución de la República Bolivariana de Venezuela, a través del cual toda persona sometida a un proceso jurisdiccional puede realizar, dentro de los plazos establecidos en la ley y en el curso de los procesos correspondientes, la formulación de los alegatos de hecho o de derecho que considere. Además, este derecho faculta al ciudadano para ejercer las acciones que beneficien sus intereses y producir las pruebas que puedan favorecerlo en el curso del proceso, en cualquier grado y estado en que se encuentre su causa. En definitiva, como sostiene Rivera Morales (2009) "el derecho constitucional de la defensa es aquel que permite que los individuos puedan acceder a los demás derechos y garantías procesales” (p. 479).

\section{El proceso penal}

El proceso como un todo es un instrumento para la justicia, como lo establece la normativa constitucional venezolana en su artículo 257. Además, determina que las leyes procesales establecerán la simplificación, uniformidad y eficacia de los trámites y adoptarán un procedimiento breve, oral y público. 
De acuerdo con la carta magna, no se sacrificará la justicia por la omisión de formalidades no esenciales. Dentro del proceso existe una modalidad especial que es el proceso penal, pero su característica resaltante es el sistema acusatorio formal, también denominado mixto, porque incluye las ventajas en los sistemas absolutos llamados inquisitivo y acusatorio, respectivamente, excluyendo sus defectos o inconveniencias. Específicamente, del sistema inquisitivo toma la atribución que da a los órganos del Estado para investigar y perseguir los hechos punibles, que considera función pública, mientras que, siguiendo el sistema acusatorio, niega al juez las facultades de investigar y acusar al mismo tiempo.

Aunque el proceso penal es la máxima expresión de la libertad, su normatividad se fundamenta en el principio de legalidad, según el cual antes de ejercer el ius puniendi, primero se debe garantizar que el proceso sea resultado de una cadena o sucesión de actos dirigidos a un fin concreto, que no es la condena — como precisamente lo han interpretado los operadores de justicia-, sino, por el contrario, la demostración de la verdad. Implica también la absolución del individuo, sea cual fuere el resultado de la realización de la justicia; es, concretamente, el fin del proceso. Sobre este particular, Von Ihering y Beling (2000; citados por Monagas, 2015) hablan del legismo procesal, es decir, la concepción de que el proceso es un orden establecido por la ley: "Un proceso penal caótico, en que rija el libre arbitro de las autoridades, exagerado, hasta la arbitrariedad, es insoportable, amarga la vida y llega a producir la descomposición del Estado" (p. 130). Es el mismo planteamiento de Francesco Carnelutti (1950; citado por Monagas 2015):

El proceso, efectivamente, es una actividad estrictamente regulada por el derecho. Si no hubiese esa regulación, el proceso no podría hacerse. Un proceso conducido con la colaboración enteramente libre de las partes, de los jueces, de los defensores, de los imprevistos de los testigos, sería una utopía.

Si bien la ley adjetiva es preconstitucional, pues emerge en el año 1998, tiene una influencia decisiva en los presupuestos constitucionales del debido proceso. El Código Orgánico Procesal Penal ha establecido un sistema estructurado en torno a la actuación de la titularidad de la acción que recae en el fiscal del Ministerio Público, en el juzgamiento por parte del órgano jurisdiccional y en los auxiliares de la investigación, así como en la defensa y el procesado.

Entre las garantías que establece el artículo 1. el Código Orgánico Procesal Penal (2012), se encuentra la necesidad de que se realice un juicio para cualquier imposición de pena, con la precisión de que no basta el mero indicio, sino que se requiere la exactitud y certeza de la responsabilidad penal: 


\section{Juicio previo y debido proceso}

Artículo $1 .{ }^{\circ}$. Nadie podrá ser condenado sin un juicio previo, oral y público, realizado sin dilaciones indebidas, sin formalismos ni reposiciones inútiles, ante un Juez o Jueza, o tribunal imparcial, conforme a las disposiciones de este Código y con salvaguarda de todos los derechos y garantías del debido proceso, consagrados en la Constitución de la República Bolivariana de Venezuela, las leyes, los tratados, convenios y acuerdos internacionales suscritos y ratificados por la República.

Además de reconocer el derecho que tienen los ciudadanos a un juicio previo, el Código establece las garantías que se deben cumplir en un proceso penal justo para que sea acorde con el estado social de derecho y de justicia:

\section{Juez o jueza natural}

Artículo $7 .^{\circ}$. Toda persona debe ser juzgada por sus jueces o juezas naturales y, en consecuencia, nadie puede ser procesado ni juzgado por jueces o juezas, o tribunales ad hoc. La potestad de aplicar la ley en los procesos penales corresponde, exclusivamente, a los jueces y juezas, y tribunales ordinarios o especializados establecidos por las leyes, con anterioridad al hecho objeto del proceso.

\section{Presunción de inocencia}

Artículo $8 .^{\circ}$. Cualquiera a quien se le impute la comisión de un hecho punible tiene derecho a que se le presuma inocente y a que se le trate como tal, mientras no se establezca su culpabilidad mediante sentencia firme.

\section{Afirmación de la libertad}

Artículo 9.․ Las disposiciones de este Código que autorizan preventivamente la privación o restricción de la libertad o de otros derechos del imputado o imputada, o su ejercicio, tienen carácter excepcional, solo podrán ser interpretadas restrictivamente, y su aplicación debe ser proporcional a la pena o medida de seguridad que pueda ser impuesta.

Las únicas medidas preventivas en contra del imputado son las que este Código autoriza conforme a la Constitución de la República Bolivariana de Venezuela.

\section{Respeto a la dignidad humana}

Artículo $10 .^{\circ}$. En el proceso penal toda persona debe ser tratada con el debido respeto a la dignidad inherente al ser humano, con protección de los derechos que de ella derivan, y podrá exigir a la autoridad que le requiera su comparecencia el derecho de estar acompañada de un abogado de su confianza.

El abogado requerido, en esta circunstancia, solo podrá intervenir para garantizar el cumplimiento de lo previsto en el artículo $10^{\circ}$ de este Código.

\section{Titularidad de la acción penal}

Artículo 11. ${ }^{\circ}$ La acción penal corresponde al Estado a través del Ministerio Público, que está obligado a ejercerla, salvo las excepciones constitucionales y legales.

\section{Defensa e igualdad entre las partes}

Artículo 12. ${ }^{\circ}$. La defensa es un derecho inviolable en todo estado y grado del proceso. Corresponde a los jueces y juezas garantizarlo sin preferencias ni desigualdades. 
Los jueces y juezas, y demás funcionarios y funcionarias judiciales no podrán mantener, directa o indirectamente, ninguna clase de comunicación con alguna de las partes o sus abogados o abogadas, sobre los asuntos sometidos a su conocimiento, salvo con la presencia de todas ellas.

Finalidad del proceso

Artículo 13. ${ }^{\circ}$. El proceso debe establecer la verdad de los hechos por las vías jurídicas, y la justicia en la aplicación del derecho, y a esta finalidad deberá atenerse el juez o jueza al adoptar su decisión.

\section{Oralidad}

Artículo $14 .^{\circ}$. El juicio será oral y solo se apreciarán las pruebas incorporadas en la audiencia, conforme a las disposiciones de este Código.

\section{Publicidad}

Artículo 15. ${ }^{\circ}$. El juicio oral tendrá lugar en forma pública, salvo las excepciones de ley.

\section{Inmediación}

Artículo 16. ${ }^{\circ}$. Los jueces o juezas que han de pronunciar la sentencia deben presenciar, ininterrumpidamente, el debate y la incorporación de las pruebas de las cuales obtienen su convencimiento.

\section{Concentración}

Artículo $17 .^{\circ}$. Iniciado el debate, este debe concluir sin interrupciones en el menor número de días consecutivos posibles.

\section{Contradicción}

Artículo $18 .^{\circ}$. El proceso tendrá carácter contradictorio.

\section{Control de la constitucionalidad}

Artículo $19 .^{\circ}$. Corresponde a los jueces y juezas velar por la incolumidad de la Constitución de la República Bolivariana de Venezuela. Cuando la ley cuya aplicación se pida colidiere con ella, los tribunales deberán atenerse a la norma constitucional.

\section{Persecución}

Artículo 20. ${ }^{\circ}$. Nadie debe ser perseguido o perseguida penalmente más de una vez por el mismo hecho. Será admisible una nueva persecución penal:

1. Cuando la primera fue intentada ante un tribunal incompetente, que por ese motivo concluyó el procedimiento;

2. Cuando la primera fue desestimada por defectos en su promoción o en su ejercicio.

\section{Cosa juzgada}

Artículo 21. ${ }^{\circ}$ Concluido el juicio por sentencia firme no podrá ser reabierto, excepto en el caso de revisión conforme a lo previsto en este Código.

\section{Apreciación de las pruebas}

Artículo $22 .^{\circ}$. Las pruebas se apreciarán por el tribunal según la sana crítica observando las reglas de la lógica, los conocimientos científicos y las máximas de experiencia. 


\section{Protección de las víctimas}

Artículo 23. ${ }^{\circ}$. Las víctimas de hechos punibles tienen el derecho de acceder a los órganos de administración de justicia penal de forma gratuita, expedita, sin dilaciones indebidas o formalismos inútiles, sin menoscabo de los derechos de los imputados o imputadas o acusados o acusadas. La protección de la víctima y la reparación del daño a la que tengan derecho serán también objetivos del proceso penal.

Los funcionarios o funcionarias que no procesen las denuncias de las víctimas de forma oportuna y diligente, y que de cualquier forma afecte su derecho de acceso a la justicia, serán sancionados conforme al ordenamiento jurídico.

Para no entrar en especificidades desde el punto de vista del proceso, se cita el Código en extenso simplemente con el objetivo de enunciar cada uno de los derechos que se deben garantizar en el plano legal, por cuanto la organización deriva de un elemento racional como es el proceso.

\section{El derecho penal y los delitos políticos}

La noción del derecho penal no solo implica la determinación de los tipos penales mediante el ius puniendi, sino que además es un medio ideal para la conservación del Estado y de sus ciudadanos por cuanto materializa el empleo necesario de la fuerza en contra de la impunidad, como se expuso en apartados anteriores. De acuerdo con el principio de legalidad, solo se podrán considerar como crimen las conductas que el sistema normativo penal describe y las penas solamente se aplicarán siempre y cuando haya un juicio con garantías propias. Al respecto, cabe aclarar que en ese catálogo de tipos penales hay una diferenciación por naturaleza delictiva, es decir, se distinguen delitos económicos, políticos, comunes y delincuencia organizada. Específicamente, los delitos políticos —objeto de este trabajo- están definidos en la Sentencia 870 de la Sala de Casación Penal, proferida el 10 de diciembre de 2001:

Los delitos políticos puros son los que, animados con un móvil político, vulneran solo el derecho del Estado; los delitos políticos relativos son los que animados con un móvil político vulneran el derecho del Estado y además los derechos privados o de personas particulares.

Delitos políticos son los que afectan la organización e intereses de un Estado. Delitos sociales son los que afectan la paz social, la convivencia humana y las instituciones sociales fundamentales, por lo que van contra la humanidad y en consecuencia contra todos los Estados. 


\section{Visión actual y violaciones al debido proceso}

Negar el debido proceso es negar el estado social de derecho y de justicia. Es decir, cualquier menoscabo a esas premisas que son garantías al ciudadano, si se omiten o restringen como abuso del derecho que surge del control absoluto del Estado y de sus instituciones, correspondería a una responsabilidad del Estado por ser el garante del debido proceso. Esta situación se presenta en el tratamiento que han recibido un sinfín de ciudadanos que han sido aprehendidos por motivos políticos, lo cual muestra la criminalización de la disidencia. Sin entrar a comentar la tortura o el irrespeto a la dignidad humana, sí insistimos en que los indicios sobre el menoscabo y la transgresión de normas propias del derecho penal, tanto sustantivo como adjetivo, evidencian que actualmente ocurren arbitrariedades propias de un estado totalitario. Concretamente, la presente investigación demuestra que en Venezuela se presentan violaciones al debido proceso con base en las circunstancias que se describen a continuación.

\section{Violación al principio del juez natural}

Es importante recordar que el juez natural se concibe como la instancia competente para conocer del proceso en razones de su materia, territorio y cuantía. Es decir, su instancia está determinada por la competencia con anterioridad a la consideración del hecho, y no por tribunales accidentales o ad hoc, es decir, creados para el delito que se estudia.

Sin embargo, esta normativa está siendo vulnerada porque actualmente hay casos de civiles que están siendo juzgados por militares. Si bien en Venezuela la jurisdicción penal militar puede juzgar a civiles y militares dependiendo de la naturaleza de la conducta, el fuero de atracción para el civil debe ser que sea juzgado por la especialidad, es decir, por otro civil. Esta situación evidencia que existen tribunales militares accidentales creados ante la ausencia de jueces, lo cual constituye un menoscabo a las garantías del proceso.

\section{La parcialidad de jueces o recibimiento de órdenes superiores que menoscaban su independencia y autonomía}

La afirmación de que la separación de los órganos está siendo menoscabada se basa en que no existe la titularidad de los jueces, sino que son designados por la comisión judicial. Específicamente, se observa que en los casos en donde existe un marcado móvil político —no necesariamente los descritos como tal en el Código Penal o leyes penales, sino aquellos que pueden ser delitos comunes, pero con un 
marcado sesgo político-, los jueces solicitan autorizaciones para conceder medidas cautelares, beneficios procesales o sentencias absolutorias, lo cual evidencia que el poder político permea las instancias jurisdiccionales sin arreglo a la verdad y que las actuaciones obedecen al capricho del gobernante de turno.

\section{Detenciones ilegales y/o arbitrarias}

Aunque el sistema constitucional y procesal penal establece como principio general la libertad, organismos de inteligencia del Estado detienen a personas por investigaciones y las someten a tratos crueles e inhumanos. Además, a pesar de que la ley ordena que luego de cuarenta y ocho horas de la detención deben ser presentados ante el Tribunal de Control, estos pasan semanas e incluso meses en ser presentados ante los jueces correspondientes y en obtener información sobre este para el efectivo ejercicio de la defensa.

Reiteradamente se observa que estos organismos detienen a personas muchas veces jóvenes universitarios- en las afueras de sus recintos sin que tengan algún tipo de vinculación a hechos delictivos, sino simplemente por su participación o por exigir algún derecho conculcado.

\section{Tipos penales que no corresponden a la conducta realizada por el presunto partícipe}

La jurisdicción penal militar se ha aplicado sin discriminación alguna a ciudadanos que no ostentan la condición militar, a pesar de que no es del tipo correspondiente e incluso sencillamente en ausencia de acto. Al respecto se debe tener en cuenta que "los escritores que como Beling P. Merkel y Emilio González López consideran la acción como elemento integrante de la tipicidad, miran como es lógico la falta de acto como ausencia de tipo".

Asimismo, es importante destacar que en algunos casos la conducta que se alude bajo la premisa de la imputabilidad objetiva determina que el tipo penal que se acusa no es un tipo encuadrado en actividad sino de resultado. Respecto a esta diferencia, Juan Luis Modolell González (2000) expresa en su obra Temas penales:

A los fines de aprovechar al máximo la relevancia dogmática del concepto "resultado", este debe ser definido en su sentido tradicional, es decir, como toda modificación del mundo exterior espacio-temporalmente separada de la conducta, producida causalmente por esta, siendo, además exigida dicha modificación por el legislador para la consumación del tipo. Esta clase de delitos el legislador exige algo más que la simple conducta del autor para la consumación, por lo tanto si la modificación del mundo exterior se confunde con la propia conducta o con parte de ella... (p. 193) 
Con respecto a este aspecto y acogiendo la imputación objetiva señalada anteriormente, es menester agregar algunas nociones propuestas por el doctrinario Alejandro Rodríguez Morales (2006) en Sintesis de derecho penal. Parte general. En consonancia con Modolell (2006), en esta obra Rodríguez explica que la doctrina de la imputación objetiva de Claus Roxin —-mundialmente aceptada por la dogmática penal moderna - se basa en que no se desarrolla la atribución de un hecho punible por solo la causación de un cierto resultado, sino que también es preciso determinar si ello es objetivamente imputable al individuo, pues no toda producción de un daño se comprenderá como abarcada por el tipo objetivo de que se trate. Esta teoría supera el nexo causal hasta ahora aceptado y se sustenta en dos elementos que le son propios y que aventajan el nexo causal y la causa eficiente: (1) que la conducta cree un riesgo jurídico penalmente relevante, y (2) que el riesgo se transforme en el resultado concreto. Al respecto, Rodríguez (2006) precisa ut supra:

Se considera que la teoría de la imputación objetiva debe ser admitida en el Derecho Penal y recurrir a la misma, ya que solo mediante tal criterio valorativo es que se podrá determinar si una determinada conducta, más allá de haber causado un daño, ha constituido un ataque objetivo al bien jurídico protegido, que es lo que precisamente quiere evitar el legislador, por lo que de acuerdo con este entendimiento se propugna que ha de verificarse no solo en los delitos de resultados sino también en los de mera actividad, así como en los delitos imperfectos (tentativa acabada e inacabada). En tal virtud, aquí se sostiene que no ha de imputarse simplemente un resultado (como se entendía al surgir el concepto de imputación objetiva) o un comportamiento, sino más bien el tipo objetivo en tanto ejecución de un ataque contra el bien jurídico protegido. (p. 261)

En definitiva, muchas veces no se evidencia que los resultados imputados, acusados y condenados existieron ni mucho menos puede atribuirse a los ciudadanos que se involucran.

\section{Ocultamiento o silenciamiento de pruebas}

Muchas veces los auxiliares de investigación no permiten el acceso a la prueba y en otros casos no son valoradas, lo cual se concibe como una violación de los derechos constitucionales. Hay que aclarar que toda violación del procedimiento constituye una infracción al debido proceso, al derecho a la defensa y a una tutela judicial eficaz. Sobre este particular, la Sala Constitucional determinó que "la falta de apreciación de las pruebas en un determinado contexto puede constituir la violación del derecho de defensa de una de las partes, pero en otros casos no pasa de ser una transgresión netamente formal sin ningún peso sobre dicho derecho" (Sentencia 355 del 2001). 


\section{El derecho penal del enemigo}

A pesar de que Venezuela ha utilizado el régimen garantista basado en el sistema acusatorio, es indudable que ha empleado el derecho penal del enemigo, como evidencian los casos expuestos en desmedro del estado de derecho. Específicamente, la tesis del derecho penal del enemigo sostiene que el delincuente es un enemigo público, de tal manera que el Estado procede de dos modos con los delincuentes: puede ver en ellos personas que delinquen, porque han cometido un error, o individuos a los que hay que impedir, mediante la coacción, que destruyan el ordenamiento jurídico (Jakobs; citado por Modolell, 2006, p. 208).

Jakobs entiende como un mal la penetración del derecho penal del enemigo en el derecho penal, desde la perspectiva del estado de derecho (parece preferir la creación de un derecho de excepción). Pone el ejemplo de cómo en Alemania la punición de actos preparatorios de delitos de terrorismo se traslada a simples robos.

\section{Conclusiones}

Al finalizar esta investigación se debe resaltar el papel preponderante del estado de derecho, entendido como un sistema totalmente democrático, profundamente garantista y, sobre todo, en el que existen reglas preestablecidas que regulan aspectos bajo su imperio. En este sentido, la relación entre democracia y derecho permite la confluencia de un equitativo, pero a la vez riguroso, sistema donde las normativas legales propenden a generar bienestar y tranquilidad.

La antítesis al derecho es el totalitarismo. Si bien las actividades que se traducen en violaciones a los derechos de los justiciables o del ciudadano sometido a procesos penales por delitos políticos pueden ser resueltas en el plano institucional, en el estado totalitario o absoluto la discrecionalidad del funcionario se agudiza y no permite que el ciudadano tenga un accionar libre, sino que, por el contrario, este vive en una permanente incertidumbre sobre los riesgos tanto a la libertad como al debido proceso.

Por lo tanto, respecto al enfoque que se debe establecer en el proceso social vigente es menester concluir:

1. La democracia es el único régimen político que puede garantizar un estado de derecho, basado simplemente en el ejercicio pleno y reconocimiento de parte de la sociedad política de la sociedad civil, con el sometimiento a una estructura constitucional que tenga un sostenimiento de la soberanía popular. 
2. El estado de derecho se debe sustentar en una comunidad de principios, los cuales deben estar previamente establecidos en una constitución escrita, lo cual implica una estructura que garantice la supremacía de ella y que someta tanto los órganos como a los ciudadanos, sin distingo. Asimismo, debe existir un sistema de justicia constitucional que restablezca el orden público constitucional cuando se presenten violaciones o menoscabo del estado de derecho.

3. La plena convicción de un sistema democrático permite concluir que en Venezuela sí hay un desbalance, pues el poder político tiene injerencia en el judicial, en menoscabo de la separación de poderes. Por ende, se evidencian trastornos donde el ejecutivo decide sobre aspectos que el judicial tiene como función ordenar. Como es un problema que incumbe a todos los ciudadanos, cualquiera puede ejercitar el agotamiento de la instancia nacional y acudir a la internacional.

4. Si el estado de derecho está conculcado en el ámbito interno y no existen mecanismos constitucionales que coadyuven, la ciudadanía podrá utilizar el control de la convencionalidad en el caso de América Latina, a través de la Convención Interamericana de Derechos Humanos o Pacto de San José como medio de restablecimiento ${ }^{4}$.

5. Las violaciones a los Derechos Humanos o fundamentales, como es el debido proceso, deben ser denunciadas e incluso propiciar la activación de los mecanismos conducentes para su restablecimiento. Asimismo, es necesario insistir en el ejercicio de las acciones penales, civiles, administrativas y disciplinarias que hubiere lugar en contra de los ciudadanos que los violen o menoscaben en el uso de la autoridad.

El principio de libre autodeterminación de los pueblos no puede ser excusa para que en el fuero interno se permitan violaciones a los derechos fundamentales so pena y excusa del cumplimiento de órdenes o por el juego político de turno. Por el contrario, debe responder a la garantía de un conjunto de principios de apoyo sistemático de todos los países del hemisferio en el reconocimiento de los Derechos Humanos y/o fundamentales.

4 Es necesario señalar que a pesar de que el gobierno venezolano la demandó, la Comisión sigue vigente como norma de Derechos Humanos. 


\section{Conflicto de intereses}

Los autores declaran que no existe ningún potencial conflicto de interés relacionado con este capítulo.

\section{Financiación}

Los autores no declaran fuente de financiamiento para la realización de este capítulo.

\section{Referencias}

Bello Tabares, H. (2004). Tutela judicial efectiva y otras garantías constitucionales procesales. Caracas: Paredes.

Bracho, P. (2000). Fundamentos de Derecho Público. Una estrategia para su estudio (5. a ed.). Vadell Hermanos Editores.

Chalbaud, R. (1999). Estado y politica. Ediciones Liber.

Constitución de la República Bolivariana de Venezuela. (2009). Gaceta Oficial n. 5908.

Modolell, J. (2006). Temas penales. Universidad Católica Andrés Bello.

Monagas, O. (2015). El proceso penal democrático. El proceso penal justo. Marcial Pons.

Presidencia de la República. (2012). Decreto con rango, valor y fuerza de ley del Código Orgánico Procesal Penal. Gaceta Oficial n. ${ }^{\circ} 6078$.

Rivas, A. (2004). Derecho constitucional. Clemente Editores.

Rivas, A. (2008). El Estado, estructura y valor de sus instituciones (4. ${ }^{\mathrm{a}}$ ed.). Clemente Editores.

Rivera, R. (2009). Recursos procesales (3. ${ }^{\text {a ed. }) . ~ L i b r e r i ́ a ~ J . ~ R i n c o ́ n ~ G . ~}$

Rodríguez, A. (2006). Sintesis de derecho penal. Parte general. Ediciones Paredes.

Villar, L. (2007). Estado de derecho y estado social de derecho. Revista Derecho del Estado, 20, 73-96. https://revistas.uexternado.edu.co/index.php/derest/article/view/705/667 